\title{
Pemanfaatan Sistem Informasi Geografis untuk Pemetaan Penyakit Periodontal Berdasarkan Faktor Lingkungan Di Kecamatan Pundong, Kabupaten Bantul
}

\author{
Prayudha Benni Setiawan $^{1^{*}}$, Bekti Nur'aini ${ }^{1}$ Hartono $^{2}$, Regina Titi Christinawati Tandelilin ${ }^{1,3}$ \\ ${ }^{1}$ Program Studi Higiene Gigi, Fakultas Kedokteran Gigi, Univeritas Gadjah Mada, Yogyakarta \\ ${ }^{2}$ Fakultas Geografi, Universitas Gadjah Mada, Yogyakarta \\ ${ }^{3}$ Departemen Biologi Oral, Fakultas Kedokteran Gigi, Universitas Gadjah Mada, Yogyakarta \\ *Corresponding author: prayudha.benni.s@ugm.ac.id
}

Info Artikel : Diterima Juli 2019 ; Disetujui September 2019 ; Publikasi Oktober 2019

\begin{abstract}
ABSTRAK
Latar belakang: Penyakit periodontal merupakan salah satu penyakit gigi dan mulut yang banyak di jumpai di masyarakat dunia khususnya di Indonesia. Penyebab utama penyakit periodontal adalah faktor lokal yaitu bakteri plak dan kalkulus. Selain itu faktor geografis, lingkungan secara tidak langsung dapat mempengaruhi individu mengalami penyakit periodontal. Sistem Informasi Geografis (SIG) dapat digunakan untuk menganalisis perbedaan faktor-faktor tersebut, terutama yang berhubungan dengan perbedaan geografis dan lingkungan. Kecamatan Pundong memiliki variasi letak geografis dan lingkungan. Tujuan dari penelitian ini adalah mengkaji adanya pengelompokan (clustering) kasus dan hubungan faktor lingkungan dengan keparahan penyakit periodontal penyakit periodontal di Kecamatan Pundong tahun 2016.

Metode: Jenis penelitian ini adalah observasional analitik survei dengan disain cross-sectional. Subjek penelitian ditetapkan dengan pendekatan Regristry Based Study dimana Puskesmas Pundong sebagai sumber data dasar dalam penelitian ini. Variabel bebas adalah penyakit periodontal, sedangkan variabel terikat adalah ketinggian tempat (geografis) dan pH air (lingkungan). Analisis spasial menggunakan Purely Spatial Poisson Model Sat Scan dan ArcGIS.Distribusi frekuensi dan hubungan faktor lingkungan dengan penyakit periodontal dianalisis menggunakan univariat dan bivariat.

Hasil: Variabel yang berhubungan secara signifikan dengan keparahan penyakit periodontal yaitu pH sumber air dan ketinggian tempat $(p$-value $<0,05)$. Berdasarkan analisis Purely Spatial Poisson Model didapatkan satu cluster, terjadi pada 49 penderita dengan radius $2.24 \mathrm{~km}$ terdapat di Desa Seloharjo. Memiliki annual cases 11.2/100000 penduduk, yang berarti dalam 100000 penduduk memiliki 11.2 mengalami kasus penyakit periodontal.

Simpulan: Terdapat hubungan yang signifikan keparahan penyakit periodontal dengan pH sumber air dan ketinggian tempat. Berdasarkan analisis spasial terdapat klaster kejadian periodontal di Desa Seloharjo.
\end{abstract}

Kata kunci: Penyakit Periodontal; Geografis; Lingkungan; SIG

\section{ABSTRACT}

Title: Using Geographic Information System for Periodontal Disease Mapping Based on Environmental Aspects in Pundong District, Bantul Regency

Background: Periodontal disease is one of the most common oral diseases in the world, especially in Indonesia. The main causes of periodontal disease are local factors such as dental plaques and calculus. In addition, environmental factors can indirectly affect individuals experiencing periodontal disease.Geographical Information Systems (GIS) can be used to analyze differences in these factors, especially those related to geographical and environmental differences. Pundong district has geographical and socio-economic variation. The aim of this study was to analyze the clustering of cases and the relationship of environmental factors to the severity of periodontal disease in Pundong District in 2016 
Methods: The type of study was an observational analytic survey with a cross-sectional design. The subject of research is determined by Registry Based Study approach where Pundong Community Health Center as the primary data source in this research. Independent variable is periodontal disease, while the dependent variable is a altitude and water acidity. Spatial analysis using Purely Spatial Poisson SatScan and ArcGIS. The distribution and relationship of environmental factors with periodontal disease were analyzed using univariate and bivariate

Results: The variables significantly associated with periodontal disease severity were altitude and water acidity (p-value <0.05). Spatial analysis to determine the cluster of incidence of periodontal disease, with Purely Spatial Poisson Model analysis obtained 1 cluster, occurred in 49 patients with radius $2.24 \mathrm{~km}$ in Seloharjo. It has annual cases of 11.2 / 100000 residents, which means that in 100000 the population has 11.2 cases of people.

Conclusion: There is a significant relationship between the severity of periodontal disease and the water acidity and altitude. Based on the spatial analysis there were cluster periodontal events in Seloharjo.

Keywords: Periodontal Disease; Geographic; Environment; GIS

\section{PENDAHULUAN}

Gingivitis dan periodontitis merupakan penyakit periodontal yang sering ditemui. Pada proses perkembangan perjalanan penyakit periodontal, terdapat tiga tahap penting, yaitu pertama terjadi peradangan pada gusi (gingivitis), kedua apabila keadaan ini dibiarkan menjadi kerusakan serabut periodontal yang menyebabkan hilangnya jaringan penyangga yang tidak dapat diatasi (periodontitis), apabila proses ini tidak dihentikan maka tahap ketiga begitu banyak tulang mandibula hilang sehingga ekstraksi elemen gigi geligi tidak dapat dihindarkan. ${ }^{1}$ Penyakit periodontal sering sekali disertai dengan rasa sakit, ketidaknyamanan, dan mempengaruhi fungsi fisik yang tepat seperti mengunyah. ${ }^{2}$

Penyakit periodontal merupakan salah satu penyakit gigi dan mulut yang banyak di jumpai di masyarakat dunia khususnya di Indonesia. Penyakit periodontal yang banyak dijumpai adalah keradangan gusi atau gingivitis dan periodontitis. ${ }^{3}$ Data Riset Kesehatan (RISKESDAS) tahun 2013 menunjukkan prevalensi penyakit periodontal pada semua kelompok umur di Indonesia yaitu 96,58\%. ${ }^{4}$

Penyebab utama penyakit periodontal adalah faktor lokal, yaitu bakteri plak dan kalkulus yang terakumulasi pada permukaan gigi. ${ }^{5}$ Selain faktor lokal, faktor lingkungan juga mempengaruhi secara tidak langsung terhadap kejadian penyakit periodontal. Kondisi lingkungan seperti kualitas air juga memiliki pengaruh dengan kondisi periodontal individu. Peningkatan jumlah kalsium dan mineral lain dalam saliva dan plak gigi ini salah satunya disebabkan oleh karena konsumsi air dengan kandungan kalsium yang tinggi. $^{6}$ Air dengan kandungan kalsium tinggi adalah air dengan tingkat kesadahan dan $\mathrm{pH}$ yang tinggi. ${ }^{7}$

Sistem Informasi Geografis (SIG) merupakan sistem komputer yang memiliki kemampuan dalam menangani data yang bereferensi data geografis. ${ }^{8}$ Cakupan pemanfaatan SIG dalam kesehatan masyarakat diantaranya adalah untuk menilai risiko dan mengetahui distribusi penyakit. SIG dapat memberikan manfaat dalam bidang kesehatan diantaranya untuk mempelajari hubungan antara lokasi, lingkungan dan kejadian penyakit,

Beberapa penelitian SIG tentang kesehatan gigi berkaitan tenang pemetaan penyebaran penyakit gigi, seperti penelitian oleh Tiwari tahun 2016 yang menganalisis distribusi trauma gigi anak sekolah di daerah kota Curitiba yang menunjukkan terjadinya perbedaan urban dan sub urban. ${ }^{9}$ Penelitian oleh Pereira Tahun 2014, yang memetakan kejadian gingivitis pada anak umur 12 tahun, dan melihat hubungan faktor risiko kejadian gingivitis seperti gender, pendapatan, jumlah penghuni rumah, pendidikan dan frekuensi sikat gigi. ${ }^{10}$

Persentase penduduk yang memiliki permasalahan gigi dan mulut di Bantul cukup tinggi yaitu $20,7 \%$. ${ }^{11}$ Kondisi tersebut di perparah dengan pemanfaatan pelayanan kesehatan gigi dan mulut di beberapa wilayah Bantul termasuk di kecamatan Pundong yang masih rendah, hanya $8 \%$ dari total kunjungan di puskesmas yang memanfaatkan pelayanan kesehatan gigi dan mulut. ${ }^{12}$ Kondisi Kecamatan Pundong yang memiliki keberagaman kondisi geografis. Bentangan wilayah di Kecamatan Pundong $67 \%$ berupa daerah yang datar sampai berombak, 30\% berupa daerah yang berombak sampai berbukit dan $3 \%$ berupa daerah yang berbukit sampai bergunung. ${ }^{13}$ Bagian utara merupakan daerah datar dengan ketinggian 10 mil dari permukaan laut, sedangkan dibagian selatan daerah pegunungan kapur, tanahnya kurang subur akibatnya dengan ketinggian diatas 20 mil dari permukan laut. Dataran tinggi di kecamatan Pundong terletak pada Desa Seloharjo dengan ketinggian maksimal 100-500 mdpl. Berdasarkan latar belakang diatas, maka tujuan dari penelitian ini adalah untuk mengkaji adanya pengelompokan (clustering) kasus dan hubungan faktor lingkungan dengan keparahan penyakit periodontal penyakit periodontal di Kecamatan Pundong tahun 2016.

\section{MATERI DAN METODE}

Jenis penelitian ini adalah survei analitik dengan desain cross-sectional menggunakan Sistem Informasi 
Geografis untuk mengetahui pola sebaran kasus dan mencari hubungan faktor risiko terhadap penyakit periodontal di Kecamatan Pundong. Penelitian ini telah mendapatkan persetujuan Etik Penelitian Fakultas Kedokteran UGM No. $\mathrm{KE} / \mathrm{FK} / 0048 / \mathrm{EC} / 2017$.

Data yang digunakan dalam penelitian ini terdiri dari data primer dan data sekunder. Data primer diperoleh secara langsung dengan mendatangi responden dan mencatat semua data yang dibutuhkan dalam lembar panduan obeservasi dan titik koordinat lokasi penderita penyakit periodontal yang diidentifikasi dengan menggunakan alat Global Positioning System (GPS). Data lingkungan seperti tingkat derajat keasaman air minum dikategorikan menjadi dua yaitu basa $(>7,6)$ dan normal $(6,8-7,5)$. derajat keasaman air minum diukur menggunakan $\mathrm{pH}$ digital. Data ketinggian tempat tinggal dengan kriteria tinggi $(>100 \mathrm{mdpl})$ kategori rendah $(\leq 100 \mathrm{mdpl})$. Sedangkan data sekunder diperoleh dari catatan rekam medis kasus penyakit periodontal di Puskesmas Pundong selama tahun 2016 (Januari hingga Desember). Subjek kasus dalam penelitian ini adalah seluruh pasien penderita penyakit periodontal pada tahun 2016 di wilayah kerja Puskesmas Pundong sebanyak 152 subjek. Keparahan penyakit periodontal dapat diklasifikasikan menurut distibusi, yaitu localized periodontitis dan generalize peridodontitis. Localized periodontitis ditandai dengan kehilangan serabut kolagen pada ligamen periodontal yang melibatkan sekelompok gigi saja, sedangkan generalized aggressive periodontitis sudah melibatkan beberapa regio gigi.

Data yang sudah terkumpul kemudian dianalisis. Peta distribusi kejadian penyakit periodontal dibuat menggunakan software arcgis, dengan metode overlay atau menggabungkan beberapa layer seperti peta administrasi Kecamatan Pundong, peta kontur ketinggian, dan koordinat lokasi penderita penyakit periodontal. Untuk mengetahui adanya clustering pada kejadian penyakit periodontal dilakukan analisis dengan purely spatial scan statistic menggunakan software sat scan. Analisis data untuk melihat distribusi frekuensi dan hubungan faktor derajat keasaman air minum dan ketinggian tempat dengan penyakit periodontal dianalisis menggunakan univariat dan bivariate.

\section{HASIL DAN PEMBAHASAN}

HASIL

Tabel 1. Hasil analisa statistik hubungan variabel bebas dengan kejadian penyakit periodontal di Kecamatan Pundong tahun 2016

\begin{tabular}{|c|c|c|c|c|c|c|c|c|}
\hline \multirow{3}{*}{ Karakteristik } & \multicolumn{4}{|c|}{ Keparahan Penyakit Periodontal } & \multirow{3}{*}{$X^{2}$} & \multirow{3}{*}{ OR } & \multirow{3}{*}{$p$-Value } & \multirow{3}{*}{$95 \% \mathrm{CI}$} \\
\hline & \multicolumn{2}{|c|}{ Generalized } & \multicolumn{2}{|c|}{$\begin{array}{c}\text { Non Generalized } \\
\text { (Localized) }\end{array}$} & & & & \\
\hline & $\mathrm{n}=48$ & $\%$ & $\mathrm{n}=104$ & $\%$ & & & & \\
\hline \multicolumn{9}{|l|}{ pH sumber air } \\
\hline Basa & 47 & 97.96 & 57 & 54.37 & \multirow{2}{*}{29.77} & \multirow{2}{*}{41.142} & \multirow{2}{*}{$0.000 *$} & \multirow{2}{*}{$0.64-196.1$} \\
\hline Normal & 1 & 2.04 & 47 & 45.63 & & & & \\
\hline \multicolumn{9}{|l|}{ Ketinggian } \\
\hline Tinggi & 37 & 77.08 & 6 & 5.77 & \multirow{2}{*}{82.33} & \multirow{2}{*}{54.939} & \multirow{2}{*}{$0.000 *$} & \multirow{2}{*}{$17.24-187.79$} \\
\hline Rendah & 11 & 22.92 & 98 & 94.23 & & & & \\
\hline
\end{tabular}

Berdasarkan hasil penelitian, sebagian besar kasus penyakit periodontal memiliki $\mathrm{pH}$ sumber air yang basa yaitu sebanyak 68,42\% (Tabel 1). Berdasarkan Tabel 1, menunjukkan bahwa terdapat hubungan antara $\mathrm{pH}$ sumber air yang basa dengan keparahan penyakit periodontal dengan $p$-value $=$ $0,000(\mathrm{P}<0,05)$, dengan $\mathrm{OR}=41,14$ artinya individu yang memiliki $\mathrm{pH}$ air yang basa memiliki kesempatan menderita penyakit periodontal dengan tingkat keparahan menyeluruh gigi (generalized) 41,14 kali. Pola sebaran distribusi penyakit periodontal berdasarkan derajat keasaman air minum dapat dilihat pada gambar 1 .
Hasil tabel 1, terlihat bahwa terdapat hubungan ketinggian tempat dan keparahan penyakit periodontal dengan $\mathrm{p}$-value $=0,000(\mathrm{P}<0,05)$, dengan $\mathrm{OR}=54,93$ artinya individu yang berada di dataran tinggi memiliki kesempatan menderita penyakit periodontal dengan tingkat keparahan menyeluruh gigi (generalized) 54,93 kali. Pola sebaran distribusi penyakit periodontal berdasarkan ketinggian tempat dapat dilihat pada gambar 2. Gambar 2 memperlihatkan pola distribusi penyakit periodontitis cenderung berada di daerah pegunungan kapur yang tinggi. 


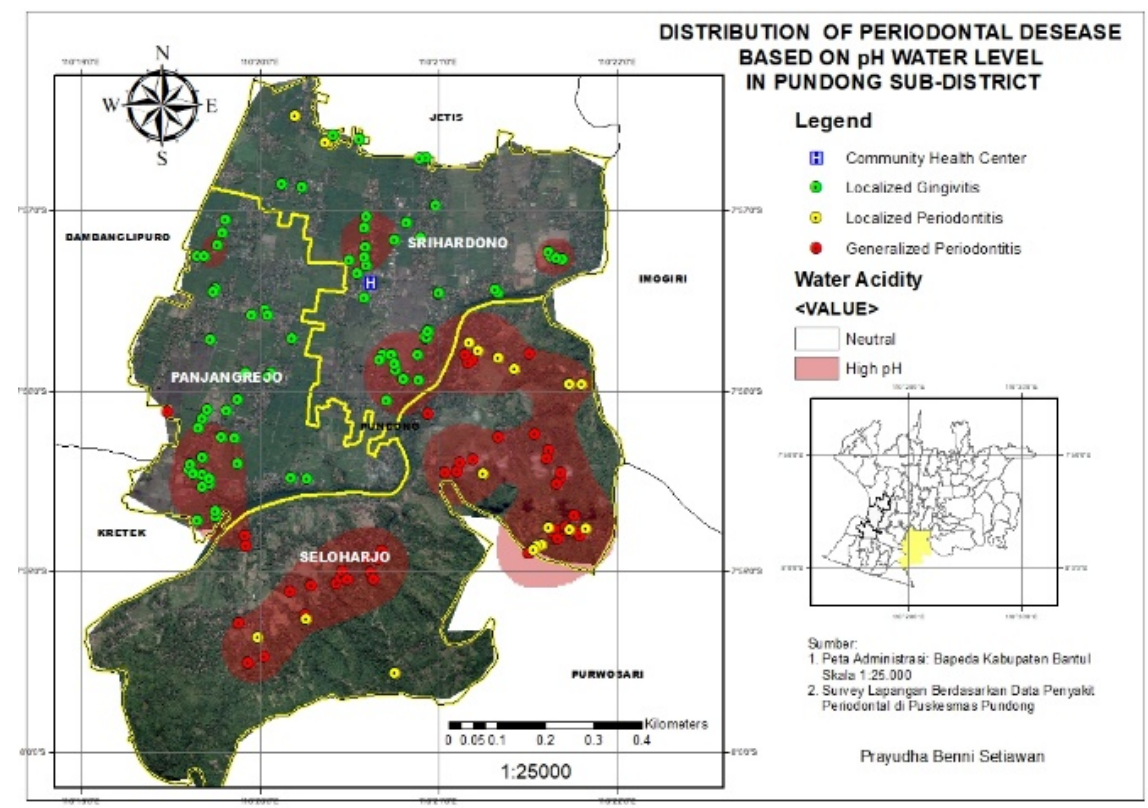

Gambar 1. Gambaran Distribusi Penyakit Periodontal Berdasarkan Derajat Keasaman Air Minum di Kecamatan Pundong

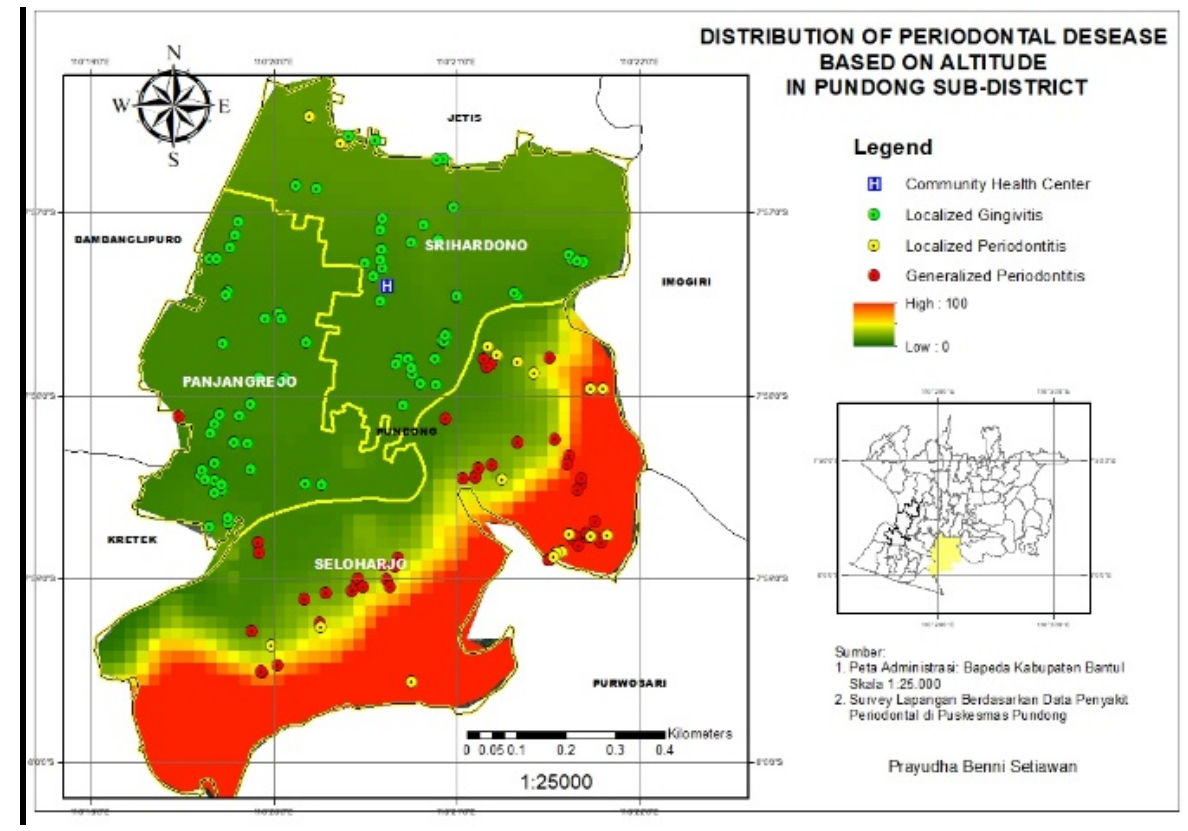

Gambar 2. Distribusi Penyakit Periodontal

Berdasarkan Ketinggian Tempat di Kecamatan Pundong.

Pada analisis spasial untuk mengetahui pengelompokan (cluster) secara kewilayahan kejadian penyakit periodontal, dengan analisis purely spatial poisson model terlihat 1 cluster kejadian periodontal berdasarkan wilayah di Kecamatan Pundong. Klaster terjadi pada 49 penderita yang berpusat pada koordinat $(7.9796 \mathrm{~S}, 110.363740 \mathrm{E})$ dengan radius
$2.24 \mathrm{~km}$ terdapat di Desa Seloharjo dengan $p$ value $=1,00$, yang berarti pengelompokan tersebut berdasarkan uji statistik tidak bermakna secara signifikan. Hal ini dikarenakan pola persebaran penyakit periodontal tidak berdasarkan pada tempattempat tertentu. Peta clustering penyakit periodontal di Kecamatan Pundong dapat dilihat pada Gambar 3. 


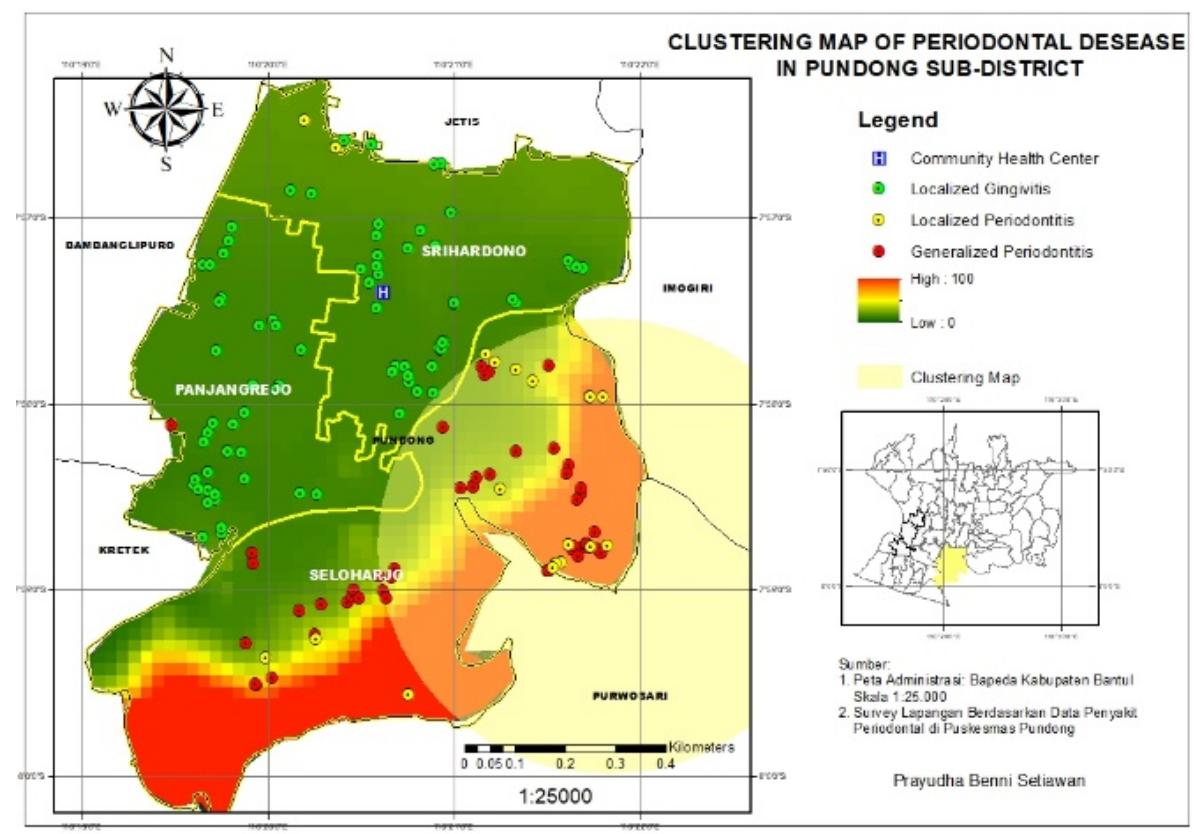

Gambar 3. Peta Clustering Penyakit Periodontal

Berdasarkan Ketinggian Tempat di Kecamatan Pundong

\section{PEMBAHASAN}

1. Hubungan $\mathrm{pH}$ Sumber Air Dengan Keparahan Penyakit Periodontal

Tabel 1 menunjukkan bahwa terdapat hubungan yang signifikan antara $\mathrm{pH}$ sumber air yang basa dengan keparahan penyakit periodontal, selain itu dapat dilihat di gambar 1 yang memperlihatkan pola distribusi penyakit periodontitis cenderung berada di daerah yang memiliki $\mathrm{pH}$ air minum yang basa (warna merah).

Hal tersebut sesuai dengan beberapa penelitian yang menyebutkan bahwa kesadahan dan $\mathrm{pH}$ air dapat mempengaruhi kesehatan gigi dan mulut. Masyarakat yang tinggal di urban tidak mendapatkan sumber air minum dari Perusahaan Air Minum (PAM), sehingga mereka mengonsumsi air sumur gali sebagai sumber air minum utamanya. Air sumur gali yang terdapat di daerah pegunungan dan pesisir mengandung derajat keasaman $(\mathrm{pH})$ yang cukup tinggi. ${ }^{14}$ Tingginya derajat keasaman ini berpengaruh terhadap jumlah kalsium dan fosfor yang merupakan bahan dalam proses pembentukan kalkulus.Apabila terjadi akumulasi kalkulus dan tidak dibersihkan, maka akan menyebabkan penyakit periodontal yang semakin parah. $^{6}$

\section{Hubungan Ketinggian Tempat Dengan} Keparahan Penyakit Periodontal

Berdasarkan hasil tabel 1, terdapat hubungan yang signifikan antara ketinggian tempat dan keparahan penyakit periodontal. Masyarakat yang tinggal di daerah berkapur atau daerah pegunungan kapur mengkonsumsi air tersebut dengan kandungan mineral air yang tinggi. Selain itu klaster terjadi di
Desa Seloharjo dengan 49 penderita, memiliki annual cases 11.2/100000 penduduk, yang berarti dalam 100000 penduduk memiliki kasus 11.2 orang. Berdasarkan Clustering penyakit periodontal berdasarkan ketinggian tempat di kecamatan Pundong (Gambar 3), terlihat bahwa pusat klaster beradadi daerah dataran tinggi pegunungan kapur.

Ketinggian pegunungan kapur berpengaruh dengan tingkat mineral di dalam air. Konsentrasi kalsium pada air minum yang melebihi standar apabila terus dikonsumsi dapat menambah kepekatan air ludah sehingga kalsium dan fosfor akan membentuk pengapuran dan menjadi kalkulus. ${ }^{15}$

Berdasarkan pembahasan, menjelaskan terdapat hubungan $\mathrm{pH}$ air dengan keparahan penyakit periodontal. Selain itu, ketinggian tempat juga mempengaruhi kadar mineral di dalam air minum. Hal tersebut berisiko terhadap penumpukan karang gigi. Oleh karena itu, perlu kerjasama lintas sector diantaranya puskesmas dan Perusahaan Daerah Air Minum memastikan ketersediaan air bersih dan layak konsumsi yang dapat diakses terhadap seluruh masyarakat. Menurut Kementerian Kesehatan tahun 2016, ketersediaan air bersih dan sesuai standart perlu dipastikan oleh pemerintah daerah. Beberapa indikator yang harus tercapai keluarga sehat diantaranya keluarga mempunyai akses/memiliki sarana air bersih, tersedianya sarana air bersih sampai memiliki sarana air bersih ke desa/kelurahan, tersedianya sarana air bersihdi sekolah/madrasah dan promosi oleh Kader kesehatan/kader PKK tentang pentingnya penggunaan air bersih dan layak konsumsi. ${ }^{16}$ 


\section{SIMPULAN}

Variabel penentu epidemiologi yang berhubungan secara signifikan dengan keparahan penyakit periodontal adalah $\mathrm{pH}$ sumber air dan ketinggian tempat. Berdasarkan analisis spasial untuk mengetahui pengelompokan (cluster) secara kewilayahan kejadian penyakit periodontal, dengan analisis purely spatial poisson model didapatkan satu cluster.

\section{SARAN}

Puskesmas bekerjasama dengan lintas sektor seperti Perusahaan Daerah Air Minum dan Dinas Pekerjaan Umum, berkaitan dengan penyuluhan penurunan angka penyakit periodontal dan bantuan air, sehingga air terstandarisasi dapat diakses ke seluruh penduduk Kecamatan Pundong

\section{DAFTAR PUSTAKA}

1. Marcuschamer E, Hawley CE, Speckman I, María R, Romero D, Nart J, et al. A lifetime of normal hormonal events and their impact on periodontal Health. Perinatol Reprod Hum. 2009;23(2):53-64.

2. Baiju R, Peter E, Varghese N, Sivaram R. Oral Health and Quality of Life : Current Concepts. J Clin Diagnostic Res. 2017;11(6):21-6.

3. Newman M, Takei H, Klokkevoid P, Carranza FA. Carranza's Clinical Periodontology, 10th. 10th ed. St.Louis Missouri: Saunders Elsevier; 2006. 46-7, 68, 72-75, 116-120. p.

4. Kemenkes. Riset Kesehatan Dasar (RISKESDAS) 2013. Jakarta; 2013.

5. Tjahja I, Lely M. Hubungan Kebersihan Gigi Dan Mulut Dengan Pengetahuan Dan Sikap Responden Di Beberapa Puskesmas Di Propinsi Jawa Barat. Media Pnelitian dan Pengegembangan Kesehat. 2005;15(1).

6. Artawa IMB, Swastini IGAAP. Perbedaan Terjadinya Karang Gigi pada Masyarakat Pengkonsumsi Air Sumur dengan Bukan Air Sumur. J Skala Husada. 2011;8(2):167-71.

7. Said NI, Ruliasih. Penghilangan Kesadahan di dalam Air Minum. In: Penghilangan Kesadadahan di Air Minum. 2008. p. 387-442.

8. Nurhayati S. Pengembangan sistem informasi pemantauan suplementasi tablet besi ibu hamil berbasis sistem informasi geografis (SIG) studi di Dinas kesehatan Kabupaten Brebes. Universitas Diponegro; 2005.

9. Tiwari N, Adhikari CMS, Tewari A, Kandpal V. Investigation of geo-spatial hotspots for the occurrence of tuberculosis in Almora district, India, using GIS and spatial scan statistic. Int $\mathbf{J}$ Health Geography. 2006;5:33.

10. Pereira SM, Ambrosano GMB, Cortellazzi KL, Tagliaferro EPS, Vettorazzi CA, Ferraz SFB, et al. Geographic information systems (GIS) in assessing dental health. Int J Environ Res Public
Health. 2010;7(5):2423-36.

11. Dinas Kesehatan Yogyakarta. Riset Kesehatan Dasar Provinsi Di Yogyakarta Tahun 2007. Yogyakarta; 2009.

12. Ati SR, Dewanto I. Gambaran Utilization Rate Pelayanan Kesehatan Gigi Dan Mulut Era Jaminan Kesehatan Nasional Di Puskesmas Piyungan, Banguntapan II Dan Banguntapan III Kabupaten Bantul Tahun 2014. Yogyakarta; 2014

13. Bappeda Bantul. Data Kecamatan Pundong [Internet]. 2016 [cited 2017 Oct 25]. Available from: https://www.bantulkab.go.id/

14. Widya CH, Nuryetty M, Sumarningsih D, Winarti Y, Ariewidayanti D, Harisah R. Indikator Kesejahteraan Masyarakat Kelautan dan Perikanan. Jakarta: Kementerian Kelautan dan Perikanan Republik Indonesia; 2011. 5 p.

15. Yusuf Y, Nisma F, Rusdi N. Analisa Kandungan Air Sumur Warga Rt12, 17 Dan 18 Rw 09 Kelurahan Kelapa Dua Wetan Kecamatan Ciracas. Jakarta Timur. Proseding Penelit Bid Ilmu Eksakta. 2011;61-87.

16. Kesehatan K. Pedoman Umum: Program Indonesia dengan Pendekatan Keluarga [Internet]. Jakarta; 2016. 57-58. 